\title{
Low calcium intake is associated with increased bone resorption in postmenopausal Japanese women: Yokogoshi Study
}

\author{
Kazutoshi Nakamura ${ }^{1, *}$, Toshiko Saito ${ }^{2}$, Akihiro Yoshihara ${ }^{3}$, Miki Ishikawa $^{1}$, \\ Yasuo Tsuchiya ${ }^{1}$, Rieko Oshiki ${ }^{4}$, Ryosaku Kobayashi ${ }^{4}$, Keiko Maruyama ${ }^{5}$, \\ Keiko Hyodo6, Mitsue Nashimoto5, Naoko Tsugawa7, Toshio Okano7, \\ Mari Oyama ${ }^{1}$ and Masaharu Yamamoto ${ }^{1}$ \\ ${ }^{1}$ Department of Community Preventive Medicine, Niigata University Graduate School of Medical and Dental \\ Sciences, 1-757 Asahimachi-dori, Niigata City 951-8510, Japan: ${ }^{2}$ Department of Health and Nutrition, Niigata \\ University of Health and Welfare, 1398 Shimami-cho, Niigata City 951-3198, Japan: ${ }^{3}$ Department of Oral \\ Health Science, Niigata University Graduate School of Medical and Dental Sciences, 2-5274 Asahimachi-dori, \\ Niigata City 951-8514, Japan: ${ }^{4}$ Department of Physical Therapy, Niigata University of Health and Welfare, \\ 1398 Shimami-cho, Niigata City 951-3198, Japan: ${ }^{5}$ Department of Nursing, Niigata University of Health and \\ Welfare, 1398 Shimami-cho, Niigata City 951-3198, Japan: ${ }^{6}$ Department of Nursing, School of Health \\ Sciences, Niigata University Faculty of Medicine, 2-746 Asahimachi-dori, Niigata City 951-8518, Japan: \\ ${ }^{7}$ Department of Hygienic Sciences, Kobe Pharmaceutical University, 4-19-1 Motoyamakita-cho, Higashinada-ku, \\ Kobe City 658-8558, Japan
}

Submitted 8 July 2008: Accepted 7 January 2009: First published online 12 March 2009

\begin{abstract}
Objective: Low Ca intake is common among Japanese women, but its effect on bone metabolism has not been fully elucidated. The aim of the present study was to determine the relationship between $\mathrm{Ca}$ intake and serum markers of bone turnover in postmenopausal Japanese women.

Design: A cross-sectional study.

Setting: A community setting.

Subjects: Subjects were 595 home-dwelling postmenopausal Japanese women. Ca intake was assessed by a validated FFQ. Serum type I collagen cross-linked N-telopeptides (NTX) and osteocalcin were measured as markers of bone turnover. The relationships between demographic characteristics, lifestyles, serum Ca, vitamin $\mathrm{D}$ and intact serum parathyroid hormone and bone turnover were also assessed.

Results: The average age of the subjects was $64 \cdot 5$ (sD 5.8) years and the mean Ca intake was 527 (SD 160) $\mathrm{mg} / \mathrm{d}$. Ca intake was significantly associated with serum NTX $(P=0 \cdot 0104)$, but not with serum osteocalcin. Mean serum NTX concentration in the lowest quartile of Ca intake $(<417 \mathrm{mg} / \mathrm{d})$ was significantly higher than in the fourth, referent quartile. Among these Japanese postmenopausal women, very low Ca intake (less than $\sim 400 \mathrm{mg} / \mathrm{d}$ ) was associated with increased bone resorption but not bone formation.

Conclusions: Increased bone resorption may be one mechanism by which this Ca-depleted population normalizes bone metabolism and prevents osteoporosis.
\end{abstract}

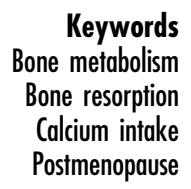

Low Ca intake is recognized as a risk factor for osteoporosis and osteoporotic fractures in postmenopausal women. Daily Ca intake of at least $1200 \mathrm{mg}$ is recommended for postmenopausal women ${ }^{(1,2)}$. However, Ca intake among Japanese women and other East Asian populations is typically well below present recommendations. The National Nutrition Survey of Japan (2003) showed that the average daily $\mathrm{Ca}$ intake of peri- and postmenopausal Japanese women was only $562 \mathrm{mg}^{(3)}$. This is lower than present clinical guidelines and also lower than that of people in many European and North American countries. Nevertheless, the incidence of hip fractures in Japan has been estimated to be less than half that in the USA ${ }^{(4)}$, suggesting that the prevalence of osteoporosis in Japan is also lower. This paradox may partly be explained by the fact that populations consuming Ca-depleted diets exhibit physiological adaptations that maintain normal bone metabolism. However, the relationship between $\mathrm{Ca}$ intake and bone 
metabolism in populations with low $\mathrm{Ca}$ intake has not been well studied.

Previous studies have demonstrated that a higher rate of bone turnover leads to bone loss, disruption of trabecular networks and reduced connectivity, and that bone turnover markers indicating bone resorption predict subsequent osteoporotic fractures independent of bone mineral density ${ }^{(5)}$. In fact, high bone remodelling may be a primary cause of osteoporotic bone fragility ${ }^{(6)}$. Markers of bone turnover can thus be used to assess the relationship between $\mathrm{Ca}$ intake and clinically significant aspects of bone metabolism. The aim of the present study was to determine the relationship between $\mathrm{Ca}$ intake and two serum markers of bone turnover - serum type I collagen cross-linked N-telopeptides $(\mathrm{NTX})^{(7,8)}$ and osteocalcin $^{(9)}$ - among postmenopausal Japanese women with low Ca intake.

\section{Subjects and methods}

\section{Subjects}

On 31 March 2006, we targeted all 1310 women aged 55-74 years who lived in the town of Yokogoshi, Japan. Of these women, 667 women agreed to participate and underwent measurement of serum bone turnover markers in the baseline investigation of the Yokogoshi Study, a community-based, epidemiological study on bone health for postmenopausal women ${ }^{(10)}$. The medical examination was conducted in November 2005. All subjects were non-institutionalized, ambulatory and independent. The following women who had medical histories that may have affected bone metabolism were excluded from analysis: (i) twelve women with a history of bilateral oophorectomy; (ii) seven women who had undergone corticosteroid therapy; and (iii) fifty-three women treated with bisphosphonates, selective oestrogen receptor modulators, active vitamin D analogues, vitamin $\mathrm{K}$ (menatetrenone), oestrogen or calcitonin for suspected osteoporosis. Ultimately, 595 of 667 women were analysed. Written informed consent was received from all subjects. The study protocol was approved by the Ethics Committee of Niigata University School of Medicine. Further details of the Yokogoshi Study have been published elsewhere ${ }^{(10)}$.

\section{Biochemical measurements}

A fasting blood specimen was drawn during the daytime, at least $6 \mathrm{~h}$ following the last ingestion of any food or drink. Each specimen was immediately maintained at $4{ }^{\circ} \mathrm{C}$ and the serum was obtained within the day of collection by centrifugation at $1613 \boldsymbol{g}$ for $10 \mathrm{~min}$. The specimen was subsequently stored at $-80^{\circ} \mathrm{C}$ prior to biochemical analysis. Serum NTX concentration, a marker of bone resorption, was determined by ELISA (Osteomark NTX Serum; Ostex International, Inc., Seattle, WA, USA; reference value: $10 \cdot 7-24 \cdot 0 \mathrm{nmol} \mathrm{BCE} / \mathrm{l}$, which had an inter-assay $\mathrm{CV}$ of $2 \cdot 8 \%$. Serum osteocalcin concentration, a marker of bone formation, was determined by an immunoradiometric assay (Mitsubishi Kagaku Medical, Inc., Tokyo, Japan; reference value: $3 \cdot 1-12 \cdot 7 \mathrm{ng} / \mathrm{ml}$ ) with an inter-assay $\mathrm{CV}$ of $6 \cdot 6 \%$. Serum vitamin D concentration, measured as 25-hydroxyvitamin D (25(OH)D), was determined by RIA (DiaSorin, Stillwater, MN, USA) with an inter-assay CV of $9.9 \%$. Serum intact parathyroid hormone (PTH) concentration was measured with a two-site immunoradiometric assay (Nichols Institute Diagnostics, San Clemente, CA, USA), which has an inter-assay CV of $1.5 \%$.

\section{Otber measurements}

Age, medical history, reproductive history, current medication list and lifestyle information were obtained from all patients. Current $\mathrm{Ca}$ intake was assessed with a previously validated FFQ for the Japanese diet ${ }^{(11)}$, with the correlation coefficient between values measured by this method and the conventional $3 \mathrm{~d}$ diet record being 0.668 . Physical activity levels were assessed based on whether subjects engaged in the following activities at least once weekly: (i) light exercise, such as gate ball (or croquet), taking walks, etc., as light activity; and (ii) moderate exercise, such as farm work, gardening, etc., as moderate activity. Body height and weight of the subjects in light underwear were measured to the nearest $1 \mathrm{~mm}$ and $100 \mathrm{~g}$, respectively. BMI was calculated by dividing body weight $(\mathrm{kg})$ by the square of body height $\left(\mathrm{m}^{2}\right)$.

\section{Statistical analysis}

All continuous variables were assessed for normality. Serum NTX and intact PTH concentrations were skewed to higher values, and thus they were transformed logarithmically when conducting statistical tests. Categorical variables, such as 'light exercise' and 'moderate exercise', were coded as 0 for 'no' and 1 for 'yes'. Pearson's product moment correlation coefficients were calculated to evaluate an association between two continuous variables. Student's $t$ test was used to test associations between physical activity measures and the two serum bone turnover markers. A stepwise method of multiple regression analysis was used to explore independent variables associated with outcome variables. Candidate predictor variables were significant variables obtained by the bivariate analyses. Analysis of covariance with Dunnett's multiple comparisons was used to compare one reference mean value with other mean values. Computations were performed using the SAS statistical software package release 8.02 (SAS Institute Inc., Cary, NC, USA). A $P$ value less than 0.05 was considered statistically significant.

\section{Results}

Characteristics of the subjects are shown in Table 1. Regarding physical activity, 569 (95.6\%) subjects engaged in light activity and $293(49 \cdot 2 \%)$ engaged in moderate activity. Serum markers of bone turnover may have an intra-day fluctuation. Nevertheless, there was no 
significant difference in mean log-transformed serum NTX concentration between subjects who underwent blood collection in the morning and in the afternoon $(P=0 \cdot 3234)$. The mean serum osteocalcin concentration among samples collected in the afternoon $(10.3 \mathrm{mg} / \mathrm{ml})$ was significantly higher $(P=0 \cdot 0486)$ than among those collected in the morning $(9 \cdot 6 \mathrm{mg} / \mathrm{ml})$.

Correlation coefficients between predictor variables and log-transformed serum NTX or osteocalcin concentration are shown in Table 2. Age, weight, BMI, Ca intake and log-transformed serum intact PTH concentration were significantly correlated with log-transformed

Table 1 Demographic and laboratory characteristics of the study subjects: home-dwelling postmenopausal Japanese women (n 595), Yokogoshi Study, 2006

\begin{tabular}{|c|c|c|c|}
\hline & $n$ & Mean & SD \\
\hline Age (years) & 595 & $64 \cdot 5$ & $5 \cdot 8$ \\
\hline Years since menopause & 578 & $14 \cdot 5$ & $6 \cdot 9$ \\
\hline Height $(\mathrm{cm})$ & 595 & $150 \cdot 7$ & $5 \cdot 5$ \\
\hline Weight (kg) & 595 & $53 \cdot 1$ & $8 \cdot 4$ \\
\hline BMI $\left(\mathrm{kg} / \mathrm{m}^{2}\right)$ & 595 & $23 \cdot 4$ & 3.5 \\
\hline Total Ca intake* (mg/d) & 595 & 527 & 160 \\
\hline Serum 25(OH)D (nmol/l) & 595 & $55 \cdot 5$ & $14 \cdot 6$ \\
\hline Serum intact PTH (pmol//) & 595 & $4 \cdot 25$ & $1 \cdot 40$ \\
\hline Serum NTX (nmol BCE/l) & 595 & $21 \cdot 0$ & $6 \cdot 5$ \\
\hline Serum osteocalcin (ng/ml) & 595 & $9 \cdot 94$ & 3.95 \\
\hline
\end{tabular}

25(OH)D, 25-hydroxyvitamin D; PTH, parathyroid hormone; NTX, type I collagen cross-linked $\mathrm{N}$-telopeptides.

${ }^{*} \mathrm{Ca}$ intake from dietary sources was 518 (SD 146) mg/d. serum NTX concentration. Years since menopause, weight, BMI and log-transformed serum intact PTH concentration were significantly correlated with serum osteocalcin concentration. None of the physical activity measures was associated with the log-transformed serum NTX or osteocalcin concentration. Additionally, a correlation coefficient between $\mathrm{Ca}$ intake and log-transformed serum intact PTH concentration was of borderline significance $(r=-0 \cdot 072, P=0 \cdot 0776)$.

Results of the stepwise multiple regression analysis are shown in Table 3. Age, weight, Ca intake and logtransformed serum intact PTH concentration were independently associated with log-transformed serum NTX concentration. BMI and log-transformed serum intact PTH concentration were independently associated with serum osteocalcin concentration.

Table 4 shows mean values of serum NTX and osteocalcin concentration according to quartile relative to the highest quartile of $\mathrm{Ca}$ intake. The lowest quartile of $\mathrm{Ca}$ intake had significantly lower log-transformed serum NTX concentrations. There was no significant association, however, between $\mathrm{Ca}$ intake and serum osteocalcin concentration.

\section{Discussion}

Previous research has shown that increased bone resorption markers are associated with increased fracture risk

Table 2 Correlation coefficients $(r)$ between selected variables and serum NTX* and osteocalcin concentrations: home-dwelling postmenopausal Japanese women ( $n$ 595), Yokogoshi Study, 2006

\begin{tabular}{lrcrr}
\hline & \multicolumn{2}{c}{ Serum NTX* } & \multicolumn{2}{c}{ Serum osteocalcin } \\
\cline { 2 - 4 } Variable & \multicolumn{1}{c}{$r$} & $P$ value & $r$ & $P$ value \\
\hline Age (years) & 0.081 & 0.0482 & -0.019 & 0.6376 \\
Years since menopause & 0.004 & 0.9318 & -0.084 & 0.0442 \\
Height $(\mathrm{cm})$ & -0.023 & 0.5703 & -0.018 & 0.6574 \\
Weight $(\mathrm{kg})$ & -0.113 & 0.0060 & -0.115 & 0.0049 \\
BMI $\left(\mathrm{kg} / \mathrm{m}^{2}\right)$ & -0.105 & 0.0102 & -0.115 & 0.0051 \\
Ca intake (mg/d) & -0.096 & 0.0194 & -0.020 & 0.6200 \\
Serum 25(OH)D (nmol/) & 0.049 & 0.2355 & -0.052 & 0.2038 \\
Serum intact PTH ${ }^{*}(\mathrm{pmol} / \mathrm{l})$ & 0.089 & 0.0302 & 0.100 & 0.0149 \\
\hline
\end{tabular}

NTX, type I collagen cross-linked N-telopeptides; 25(OH)D, 25-hydroxyvitamin D; PTH, parathyroid hormone.

*Logarithmically transformed.

Table 3 Results of a stepwise multiple linear regression analysis with log-transformed serum NTX and osteocalcin concentrations as outcomes: home-dwelling postmenopausal Japanese women ( $n$ 595), Yokogoshi Study, 2006

\begin{tabular}{|c|c|c|c|}
\hline Independent variable & Regression coefficient $(\beta)$ & SE & $P$ value \\
\hline \multicolumn{4}{|l|}{ Serum NTX* } \\
\hline Age (years) & 0.00407 & 0.00193 & 0.0353 \\
\hline Weight $(\mathrm{kg})$ & -0.00374 & $0 \cdot 00132$ & 0.0048 \\
\hline Ca intake $(\mathrm{mg} / \mathrm{d})$ & -0.000179 & 0.0000695 & $0 \cdot 0104$ \\
\hline Serum intact $\mathrm{PTH}^{*}(\mathrm{pmol} / \mathrm{l})$ & 0.07806 & 0.0342 & 0.0230 \\
\hline \multicolumn{4}{|l|}{ Serum osteocalcin } \\
\hline BMI $\left(\mathrm{kg} / \mathrm{m}^{2}\right)$ & $-0 \cdot 148$ & 0.047 & 0.0017 \\
\hline Serum intact PTH* $(\mathrm{pmol} / \mathrm{l})$ & 1.03 & 0.51 & 0.0457 \\
\hline Time of blood collection ( 0 , morning; 1 , afternoon) & 0.726 & $0 \cdot 327$ & 0.0269 \\
\hline
\end{tabular}

NTX, type I collagen cross-linked N-telopeptides; PTH, parathyroid hormone.

*Logarithmically transformed. 
Table 4 Mean values of serum NTX concentration at each quartile of calcium intake: home-dwelling postmenopausal Japanese women ( $n$ 595), Yokogoshi Study, 2006

\begin{tabular}{|c|c|c|}
\hline & \multicolumn{2}{|c|}{ Serum NTX* (nmol BCE/l) } \\
\hline & Mean & $95 \% \mathrm{Cl}$ \\
\hline \multicolumn{3}{|l|}{ Ca intake $(\mathrm{mg} / \mathrm{d})$} \\
\hline Q1 $(<417)$ & $22 \cdot 6 t$ & $21 \cdot 2,24 \cdot 0$ \\
\hline Q2 $(\geq 417,<525)$ & $20 \cdot 0$ & $19 \cdot 1,20 \cdot 9$ \\
\hline Q3 $(\geq 525,<619)$ & $21 \cdot 3$ & $20 \cdot 3,22 \cdot 3$ \\
\hline \multirow{2}{*}{ Q4 ( $\geq 619)$} & $20 \cdot 2$ & $19 \cdot 4,21 \cdot 1$ (reference) \\
\hline & \multicolumn{2}{|c|}{ Adjusted $P$ for trend $=0.0135$} \\
\hline
\end{tabular}

NTX, type I collagen cross-linked N-telopeptides; Q1, first quartile; Q2, second quartile; Q3, third quartile; Q4, fourth quartile.

*Logarithmically transformed.

tMean value was significantly different from that of reference group (analysis of covariance and Dunnett's multiple comparisons, with age, weigh and log-transformed serum parathyroid hormone as covariates): $P<0 \cdot 05$.

independent of bone mineral density ${ }^{(5)}$. Therefore, the correlates of bone resorption are relevant to assessing the aetiology of osteoporotic fractures. In the present study, we measured serum NTX concentrations as a bone resorption marker. This approach is more robust because serum-based markers of bone turnover show less variability than urinebased markers ${ }^{(12)}$ and serum NTX measurements can assess bone resorption with decreased intra-subject variability ${ }^{(7)}$.

The present study demonstrated that $\mathrm{Ca}$ intake was inversely associated with serum NTX concentration. This finding has been reported previously by a small study ${ }^{(13)}$ and is consistent with previous work showing that $\mathrm{Ca}$ supplementation reduces bone resorption ${ }^{(14-16)}$. Increased bone resorption by low $\mathrm{Ca}$ intake is hypothesized to be mediated through hyperparathyroidism induced by low $\mathrm{Ca}$ intake $^{(16,17)}$. Our data, however, failed to demonstrate a significant association between Ca intake and intact PTH concentration, but rather showed that serum NTX concentration was associated with $\mathrm{Ca}$ intake independent of PTH. This suggests that a different pathophysiological mechanism may be responsible for the effects of low $\mathrm{Ca}$ intake on bone metabolism.

An additional key finding of the present study was that mean NTX concentration in the lowest quartile of Ca intake $(<417 \mathrm{mg} / \mathrm{d})$ was significantly lower than that in the highest, reference quartile $(\geq 619 \mathrm{mg} / \mathrm{d})$. Interestingly, this finding is in accordance with an epidemiological study demonstrating that the lowest quartile of Ca intake in peri- and postmenopausal Japanese women has a significantly increased risk of vertebral fracture than the highest, reference quartile ${ }^{(18)}$. Taken together, these data suggest that the lowest levels of $\mathrm{Ca}$ intake may be a particularly serious problem in this population.

Average daily $\mathrm{Ca}$ intake of most subjects in the present study was only $527 \mathrm{mg}$, lower than that recommended for peri- and postmenopausal women by the Ministry of Health and Welfare of Japan ${ }^{(19)}$. This is consistent with the National Nutrition Survey ${ }^{(3)}$, which reported that Ca intake of Japanese persons aged 50-69 years was $568 \mathrm{mg} / \mathrm{d}$ on average, much lower than that of people in many European and North American countries. Nevertheless, only a quarter of women with very low $\mathrm{Ca}$ intake exhibited increased bone resorption in the present study. Japanese people historically have had a low-Ca diet ${ }^{(20)}$ and therefore they may be physiologically adapted to low $\mathrm{Ca}$ through increased $\mathrm{Ca}$ absorption.

Although serum osteocalcin concentration is a major predictor of bone mineral density of the elderly ${ }^{(10,21)}$, the strength of the association between serum osteocalcin concentration and fracture occurrence shows considerable variation ${ }^{(5)}$. In the present study, Ca intake was not associated with serum osteocalcin concentration.

The present study also showed that low body weight or BMI is associated with high bone resorption and formation markers. The inverse association between body weight (or BMI) and bone turnover markers has been reported by others ${ }^{(22-24)}$. A number of studies have also shown that low body weight is a major predictor of bone mineral density and bone loss of the elderly ${ }^{(21,25,26)}$ and that this association may be mediated by increased bone turnover.

Exercise is known to affect bone turnover markers ${ }^{(27)}$. However, the present study did not find physical activity to be associated with bone turnover markers. One major reason for this may be that we obtained qualitative, rather than quantitative, data for physical activity, because assessment of physical activity in the elderly is difficult. Physical activity is one of the important determinants of bone health, and future studies should clarify this association in elderly populations.

One limitation of our study is that we measured only serum NTX and osteocalcin concentrations, which reflect only certain aspects of bone turnover or bone quality. Another limitation is that an FFQ is not an ideal method to evaluate Ca intake, although the FFQ used in our study was validated with improved accuracy over other FFQ. These limitations weaken the association of $\mathrm{Ca}$ intake with serum NTX concentration seen here.

In summary, the present study showed that very low Ca intake (less than $\sim 400 \mathrm{mg} / \mathrm{d}$ ) is associated with increased bone resorption in peri- and postmenopausal Japanese women. These results suggest that Ca supplementation programmes should focus on those women at highest risk. On the other hand, a population approach is also of interest because Ca intake in most adults in Japan is lower than current recommendations. Future studies are needed to develop interventions that effectively address low $\mathrm{Ca}$ intake among postmenopausal women.

\section{Acknowledgements}

The study was supported in part by a Grant-in-Aid for Scientific Research (C) No. 17590537 from the Ministry of Education, Culture, Sports, Science and Technology of Japan; a Grant-in-Aid of the Japan Medical Association 
(2005); a grant from the Japan Osteoporosis Foundation (2007); and a grant from The National Dairy Promotion and Research Association of Japan (2007). The authors had no conflict of interest. K.N., A.Y., M.I. and M.Y. designed the study. T.S. was responsible for dietary assessment; K.M., K.H. and M.N. were responsible for demographic information and medical histories; R.O. and R.K. were responsible for physical activity assessment; Y.T., N.T. and T.O. were responsible for biochemical analyses; and M.O. was responsible for statistical analysis. K.N. was a principal author of the paper, and all authors reviewed the paper. We wish to thank the staff of the Health Promotion Division, Niigata City Yokogoshi Branch Office for their help in data collection. We are also indebted to Kyowa Medex Co., Ltd and Toyo Medic Inc. for the determination of serum $25(\mathrm{OH}) \mathrm{D}$ and bone mineral density measurements, respectively.

\section{References}

1. Standing Committee on the Scientific Evaluation of Dietary Reference Intakes, Food and Nutrition Board, Institute of Medicine (1997) Dietary Reference Intakes for Calcium, Phosphorus, Magnesium, Vitamin D, and Fluoride. Washington, DC: National Academy Press.

2. Dawson-Hughes B (1998) Vitamin D and calcium: recommended intake for bone health. Osteoporos Int $\mathbf{8}$, Suppl. 2, S30-S34.

3. Society for Information on Health and Nutrition (2006) The National Health and Nutrition Survey in Japan, 2003. Tokyo: Daiichi Shuppan.

4. Fujita T (1994) Osteoporosis in Japan: factors contributing to the low incidence of hip fracture. Adv Nutr Res 9, 89-99.

5. Garnero P (2000) Markers of bone turnover for the prediction of fracture risk. Osteoporos Int 11, Suppl. 6, S55-S65.

6. Heaney RP (2003) Is the paradigm shifting? Bone 33, 457-465.

7. Eastell R, Mallinak N, Weiss S, Ettinger M, Pettinger M, Cain D, Fressland K \& Chesnut C III (2000) Biological variability of serum and urinary N-telopeptides of type I collagen in postmenopausal women. J Bone Miner Res 15, 594-598.

8. Chaki O, Yoshikata I, Kikuchi R, Nakayama M, Uchiyama Y, Hirahara F \& Gorai I (2000) The predictive value of biochemical markers of bone turnover for bone mineral density in postmenopausal Japanese women. J Bone Miner Res 15, 1537-1544.

9. Delmas PD, Eastell R, Garnero P, Seibel MJ \& Stepan J; Committee of Scientific Advisors of the International Osteoporosis Foundation (2000) The use of biochemical markers of bone turnover in osteoporosis. Osteoporos Int 11, Suppl. 6, S2-S17.

10. Nakamura K, Tsugawa N, Saito T et al. (2008) Vitamin D status, bone mass, and bone metabolism in home-dwelling postmenopausal Japanese women: Yokogoshi Study. Bone 42, 271-277.

11. Uenishi K, Ishida H \& Nakamura K (2008) Development of a simple food frequency questionnaire to estimate intakes of calcium and other nutrients for the prevention and management of osteoporosis. J Nutr Sci Vitaminol 54, 25-29.

12. Machado ABC, Hannon R \& Eastell R (1999) Monitoring alendronate therapy for osteoporosis. J Bone Miner Res $\mathbf{1 4}$, 602-608.
13. Nakamura K, Hori Y, Nashimoto M, Okuda Y, Miyazaki H, Kasai Y \& Yamamoto M (2004) Dietary calcium, sodium, phosphorus, and protein, and bone metabolism in elderly Japanese women: a pilot study using the duplicate portion sampling method. Nutrition 20, 340-345.

14. Shapses SA, Robins SP, Schwartz EI \& Chowdhury H (1995) Short-term changes in calcium but not protein intake alter the rate of bone resorption in healthy subjects as assessed by urinary pyridinium cross-link excretion. J Nutr 125, $2814-2821$.

15. Scopacasa F, Horowitz M, Wishart JM, Need AG, Morris HA, Wittert G \& Nordin BE (1998) Calcium supplementation suppresses bone resorption in early postmenopausal women. Calcif Tissue Int 62, 8-11.

16. Fardellone P, Brazier M, Kamel S, Gueris J, Graulet AM, Lienard J \& Sebert JL (1998) Biochemical effects of calcium supplementation in postmenopausal women: influence of dietary calcium intake. Am J Clin Nutr 67, 1273-1278.

17. Riggs BL, O'Fallon WM, Muhs J, O'Connor MK, Kumar R \& Melton LJ III (1998) Long-term effects of calcium supplementation on serum parathyroid hormone level, bone turnover, and bone loss in elderly women. J Bone Miner Res 13, 168-174.

18. Nakamura K, Kurahashi N, Ishihara J, Inoue M \& Tsugane S; Japan Public Health Centre-based Prospective Study Group (2009) Calcium intake and the 10-year incidence of self-reported vertebral fractures in women and men: the Japan Public Health Centre-based Prospective Study. Br J Nutr 101, 285-294.

19. Ministry of Health, Labour, and Welfare, Japan (2004) Dietary Reference Intakes for Japanese, 2005. Tokyo: Ministry of Health, Labour, and Welfare, Japan.

20. Fujita T (1994) Osteoporosis in Japan: factors contributing to the low incidence of hip fracture. Adv Nutr Res 9, 89-99.

21. Nakamura K, Saito T, Nishiwaki T, Ueno K, Nashimoto M, Okuda Y, Tsuchiya Y, Oshiki R, Muto K \& Yamamoto M (2006) Correlations between bone mineral density and demographic, lifestyle, and biochemical parameters in community dwelling Japanese women 69 years of age and over. Osteoporos Int 17, 1202-1207.

22. Ravn P, Cizza G, Bjarnason NH, Thompson D, Daley M, Wasnich RD, McClung M, Hosking $\mathrm{D}$, Yates $\mathrm{AJ}$ \& Christiansen C (1999) Low body mass index is an important risk factor for low bone mass and increased bone loss in early postmenopausal women. Early Postmenopausal Intervention Cohort (EPIC) study group. J Bone Miner Res 14, 1622-1627.

23. Rogers A, Hannon RA \& Eastell R (2000) Biochemical markers as predictors of rates of bone loss after menopause. J Bone Miner Res 15, 1398-1404.

24. Papakitsou EF, Margioris AN, Dretakis KE, Trovas G, Zoras U, Lyritis G, Dretakis EK \& Stergiopoulos K (2004) Body mass index (BMI) and parameters of bone formation and resorption in postmenopausal women. Maturitas $\mathbf{4 7}$, 185-193.

25. Dargent-Molina P, Poitiers F \& Breart G; EPIDOS Group (2000) In elderly women weight is the best predictor of a very low bone mineral density: evidence from the EPIDOS study. Osteoporos Int 11, 881-888.

26. Ooms ME, Lips P, Van Lingen A \& Valkenburg HA (1993) Determinants of bone mineral density and risk factors for osteoporosis in healthy elderly women. J Bone Miner Res $\mathbf{8}$, 669-675.

27. Adami S, Gatti D, Viapiana O, Fiore CE, Nuti R, Luisetto G, Ponte M \& Rossini M; BONTURNO Study Group (2008) Physical activity and bone turnover markers: a crosssectional and a longitudinal study. Calcif Tissue Int $\mathbf{8 3}$, 388-392. 